\title{
Hydrogen Bonding in Aromatic Alcohol-Water Clusters: A Brief Review
}

\author{
Doo-Sik Ahn, In-Sun Jeon, Sang-Hee Jang, Sung-Woo Park, Sungyul Lee, and Wonjo Cheong” \\ School of Emiromental Science and Applied Chemistry, Kumghee Liversin, Kungki-do +49-701, Korea \\ 'Department of Chemistry. Inha Lniversity. Inchon $402-751$, Korea \\ Received February 3. 2003
}

\begin{abstract}
Recent experimental and theoretical advances on the aromatic alcohol-water clusters are reviewed, focusing on the structure of the hydrogen bonding between the alcoholic $\mathrm{OH}$ group and the binding water molecules. The interplay of experimental observations and theoretical calculations for the elucidation of the structure is demonstrated for phenol-water, benzyl alcohol-water, substituted phenol-water. naphthol-water and tropolone -water clusters. Discussion is made on assigning the role (either proton-donating or -accepting) of the hydroxyl group by measuring the shifts of infrared frequency of the $\mathrm{OH}$ stretching mode in the cluster from that of bare aromatic alcohol for the experimental determination of the cluster structure.
\end{abstract}

Key Words : Hydrogen bonding. Aromatic alcohol. Water. Cluster

\section{Introduction}

Hydrogen bonding ${ }^{1.2}$ is extremely important in chemistry and biolog: profoundly affecting the properties of the molecule. It is well known. for example. that the three dimensional structures of protein are mostly the results of the hydrogen bonding between the constituting amino acids. In the aqueous solution. the interactions of the amino acids with the solvent molecules ${ }^{3-8}$ another example of hydrogen bonding. may also play a fundamental role of the structure and reaction of protein. Therefore. systematic study on the hydrogen bond can reveal invaluable information for the structure and biochemical activity of protein. Since there are extremely many solvent molecules in the solution phase. however. it is more useful to study the hydrogen bonding in the clusters ${ }^{5-23}$ consisting of a solute and a few solvent molecules.

Hydrogen bonding between the hydroxyl $(\mathrm{OH})$ group and the water molecule(s) in organic alcohol-water clusters has been studied intensively as a prototypical model for more complex system. The organic alcohol-water clusters are of moderate size for quantum chemical calculations. allowing the comparison with the experimental observations by the molecular beam and the UV-IR double resonance tecluniques. Elucidation of the structures of their confomers lying closely in energy may also give a lot of useful information for the interactions between the alcohol molecule and the water molecules in the solution phase ${ }^{24}$ on the molecular level.

In the present review we discuss recent advances on the understanding of hydrogen bonding in aromatic alcoholwater clusters. Experimental measurements and theoretical calculations of the structure binding energy: ${ }^{256}$ and infrared frequency of phenol-water. benzyl alcohol-water. substituted phenol-water $\beta$-naphthol-water and tropolone-water clusters are reviewed. Elucidation of the nature of hy'drogen bonding

To whon correspondence should be addressed. e-mail: sylee $\alpha$ ? khu.ac.ks in these clusters by the analysis of the shifts in the vibronic bands observed by spectroscopic tecluniques is exemplified. Electrostatic and steric effects of substitution at the phenyl ring on the structure of hydrogen bonding in the substituted phenol-water clusters are discussed. The $\mathrm{OH}$ stretching frequency is described in relation to the structure and the strength of the hydrogen bond in the clusters.

Phenol-water, benzyl alcohol-water and phenylpropyl alcohol-water clusters. The phenol- $\left(\mathrm{H}_{2} \mathrm{O}\right)_{\mathrm{n}}$ clusters have been studied most intensively by many investigators ${ }^{15-22}$ as the prototypical system for organic alcohol-water cluster. As depicted in Figure 1, the role of the $\mathrm{OH}$ group in the phenol$\left(\mathrm{H}_{2} \mathrm{O}\right)_{n}$ cluster can be either proton-donating or -accepting. The conformer (P11) with the proton-donating $\mathrm{OH}$ group is calculated to be of lower energy than the proton-accepting one (P12). Experimentally, only the confonmer with the proton -donating $\mathrm{OH}$ has been observed so far. and its measured binding energy is $5.47( \pm 0.09) \mathrm{kcal} / \mathrm{mol}^{27}$ The kinetic stability of the confomer with the proton-accepting $\mathrm{OH}$ group is not known. however if the latter confonmer may be observed experimentally. the different behavior of the $\mathrm{OH}$ stretching frequencies in the complexes $\mathrm{P} 11$ and $\mathrm{Pl} 2$ (significant red shift for P11 and slight blue shift for P12: see Table 1) from that of the bare phenol would be key observable for distinguishing the two confonmers.

Figure 2 presents the benzyl alcohol- $\mathrm{H}_{2} \mathrm{O}$ clusters corresponding to the phenol- $\mathrm{H}_{2} \mathrm{O}$ clusters in Figure 1. In the

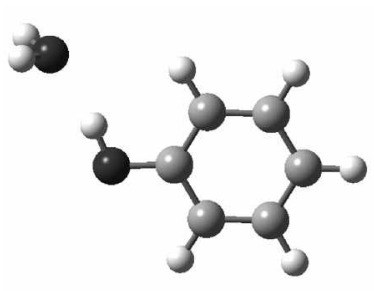

P11 (proton-donating $\mathrm{OH}$ )

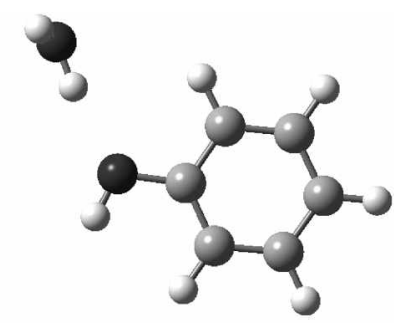

P12 (proton-accepting OH)
Figure 1. Structures of phenol- $\mathrm{H}_{2} \mathrm{O}$ complexes. 
Table 1. Calculated energies, zero point energies ( $\mathrm{PE}$ ), binding energies (BE), and $\mathrm{OH}$ stretching frequencies of phenol- $\mathrm{H}_{2} \mathrm{O}$ and substituted phenol- $\mathrm{H}_{2} \mathrm{O}$ complexes

\begin{tabular}{|c|c|c|c|c|c|c|}
\hline & $\begin{array}{l}\text { Energy }^{a} \\
\text { (Hartree) }\end{array}$ & $\begin{array}{c}\mathrm{ZPE}^{a} \\
(\mathrm{kcal} / \mathrm{mol})\end{array}$ & $\begin{array}{c}\frac{\Delta \mathrm{E}^{a}}{(\mathrm{kcal} / \mathrm{mol})}\end{array}$ & $\begin{array}{c}\mathrm{BE}^{\prime} \\
(\mathrm{kcal} / \mathrm{mol})\end{array}$ & $\begin{array}{c}v_{\mathrm{ClH}} \\
\left(\mathrm{cm}^{-1}\right)\end{array}$ & $\begin{array}{l}\text { Role of } \\
\mathrm{OH} \text { group }\end{array}$ \\
\hline $\mathrm{H}_{2} \mathrm{O}$ & -76.26397 & 13.71 & & & & \\
\hline phenol & -306.65428 & 64.95 & & & 3883.5 & \\
\hline phenol- $\mathrm{H}_{2} \mathrm{O}$ & & & & & 3706.7 & \\
\hline (P11) & -382.93428 & 80.64 & 0 & $8.07^{4}(5.48)^{c}$ & 3884.7 & p-donating \\
\hline (P12) & -382.92986 & 80.49 & +2.61 & $5.46(3.20)$ & 3885.7 & p-accepting \\
\hline p-fluorophenol & -405.72475 & 60.03 & & & & \\
\hline \multicolumn{7}{|l|}{ p-fluorophenol- $\left(\mathrm{H}_{2} \mathrm{O}\right)$} \\
\hline$(\mathrm{p}-\mathrm{f} \mathrm{P} 1 \mathrm{l})$ & -482.00546 & 75.77 & 0 & $8.47(5.86)$ & 3706.1 & p-donating \\
\hline$(\mathrm{p}-\mathrm{H} P 12)$ & -482.00026 & 75.55 & +3.04 & $5.43(2.52)$ & 3887.9 & p-accepting \\
\hline p-aminophenol & -361.87858 & 75.62 & & & 3888.9 & \\
\hline \multicolumn{7}{|l|}{ p-antinophenol- $\mathrm{H}_{2} \mathrm{O}$} \\
\hline$(\mathrm{p}-\mathrm{AP} 1 \mathrm{l})$ & 438.15794 & 91.39 & 0 & $7.65(5.09)$ & 3722.5 & p-donating \\
\hline$(\mathrm{p}-\mathrm{AP} 12)$ & -438.15472 & 91.17 & +1.85 & $5.80(2.81)$ & 38909 & p-accepting \\
\hline p-chlorophenol & -765.71075 & 59.00 & & & 3883.8 & \\
\hline \multicolumn{7}{|l|}{ p-chlorophenol- $\mathrm{H}_{2} \mathrm{O}$} \\
\hline$(\mathrm{p}-\mathrm{CPl})$ & -841.99188 & 74.75 & 0 & $8.72(6.09)$ & 3694.6 & p-donating \\
\hline$(\mathrm{p}-\mathrm{C} P 12)$ & $-8+1.98607$ & 74.47 & +3.37 & $5.35(2.45)$ & 3884.5 & p-accepting \\
\hline hydroquinone & -381.72816 & 67.45 & & & 3888.6 & \\
\hline hydroquinone- $\mathrm{H}_{2} \mathrm{O}$ & & & & & 3889.8 & \\
\hline (HQIl) & -458.00800 & 83.14 & 0 & $7.97(5.38)$ & 3717.4 & p-donating \\
\hline$(\mathrm{HQ} 12)$ & -458.00418 & 83.08 & +2.33 & $5.64(2.67)$ & 3890.7 & p-accepting \\
\hline \multicolumn{7}{|l|}{ o-tluorophenol } \\
\hline$(0-\mathrm{FPl})$ & -405.72547 & 60.19 & 0 & & 3862.1 & \\
\hline$(0-\mathrm{HP} 2)$ & -405.72109 & 59.94 & +2.50 & & 3888.6 & \\
\hline \multicolumn{7}{|l|}{ o-fluoroplnenol- $\mathrm{H}_{2} \mathrm{O}$} \\
\hline$(0-\mathrm{PPl})$ & -482.00511 & 75.86 & 0 & $7.87(4.70)$ & 3603.1 & p-donating \\
\hline$(0-\mathrm{FPl} 2)$ & -482.00225 & 75.71 & +1.63 & $6.24(3.58)$ & 3686.3 & p-donating \\
\hline$(0-\mathrm{FPl} 3)$ & -482.00081 & 75.67 & +2.50 & $5.37(2.50)$ & 38595 & p-accepting \\
\hline \multicolumn{7}{|l|}{ o-chlorophenol } \\
\hline$(0-C P 1)$ & -765.71320 & 59.24 & 0 & & 3831.8 & \\
\hline$(0-\mathrm{CP} 2)$ & -765.70886 & 59.00 & +2.49 & & 3880.8 & \\
\hline \multicolumn{7}{|l|}{ o-chlorophenol- $\mathrm{H}_{2} \mathrm{O}$} \\
\hline$(0-C P 11)$ & -841.99039 & 74.76 & 0 & $6.48(3.84)$ & 3674.6 & p-donating \\
\hline (o-CP12) & -841.98977 & 74.70 & +0.33 & $6.15(3.47)$ & 3633.7 & p-donating \\
\hline$(0-C P 13)$ & -841.98849 & 74.68 & +1.12 & $5.36(2.49)$ & 3822.9 & p-accepting \\
\hline
\end{tabular}

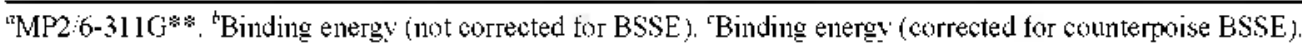

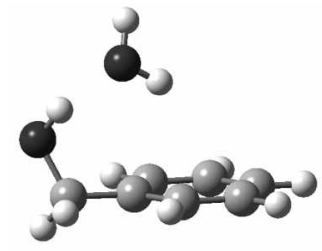

B11 (proton-donating $\mathrm{OH}$ )

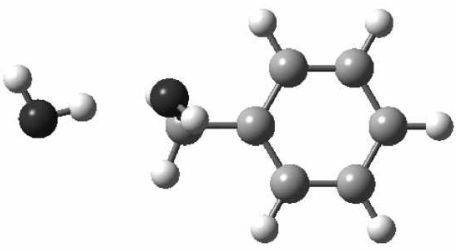

B12 (proton-accepting OH)
Figure 2. Structures of benzyl alcohol- $\mathrm{H}_{2} \mathrm{O}$ complexes.

structure (B11). the hydroxyl at the phenyl ring is a proton donor to the water molecule. while it is a proton acceptor in (B12). The lowest energy isomer corresponds to Conformer I of benzyl alcohol- $\mathrm{H}_{2} \mathrm{O}$ cluster obtained by Mikami et $\mathrm{al}^{28}$ For the benzyl alcohol- $\mathrm{H}_{2} \mathrm{O}$ cluster. the high-frequency stretching modes experimentally observed by Mikami and co-workers ${ }^{2}$ are at 3733.3622 and $3568 \mathrm{~cm}^{-1}$. assigned as antisymmetric and symmetric stretching of water molecule and the stretching of alcoholic $\mathrm{OH}$. respectively.

Figure 3 shows the phenol- $\left(\mathrm{H}_{2} \mathrm{O}\right)_{2}$ cluster $(\mathrm{P} 21)$ and the benzyl alcohol- $\left(\mathrm{H}_{2} \mathrm{O}\right)_{2}$ cluster (B21) of the lowest energy. In both clusters. the oxygen atoms of the hydroxyl and those of the two water molecules fonm a ring. In their discussions on the infrared frequencies. Mikami et al ${ }^{28}$ proposed an isomer (B22) of the benzyl alcohol- $\left(\mathrm{H}_{2} \mathrm{O}\right)_{2}$ cluster. in which a water molecule forms a $\pi$ bond to the phenyl ring. to account for the spectrum. Specifically. the observed band at $3595 \mathrm{~cm}^{-1}$. assigned as the stretching of the $\pi$-bonding water molecule. was found to be reasonably close to the harmonic frequency of 3629 computed by HF/6-31G(d.p) method

The most stable phenol- $\left(\mathrm{H}_{2} \mathrm{O}\right)_{3}$ cluster is well-known and has been studied by many groups. In this structure (P31) the four oxygen atoms form a ring as shown in Figure 4 . Since the alcoholic hydroxyl group lies almost in the phenyl ring. the four-membered ring lies beyond the phenyl ring. The isomer of the benzyl alcohol- $\left(\mathrm{H}_{2} \mathrm{O}\right)_{3}$ cluster of the lowest 


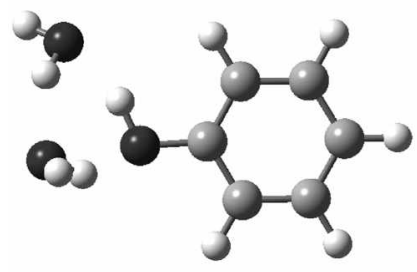

P21

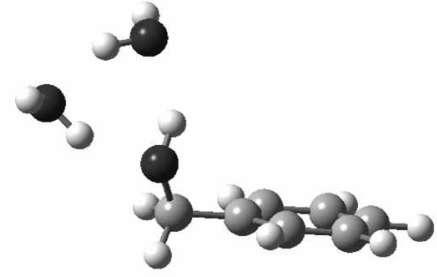

B21

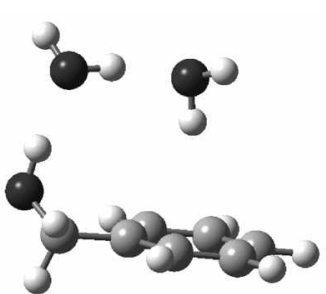

B22

Figure 3. Structures of lowest-energy phenol- and benzyl alcohol- $\left(\mathrm{H}_{2} \mathrm{O}\right)_{2}$ clusters

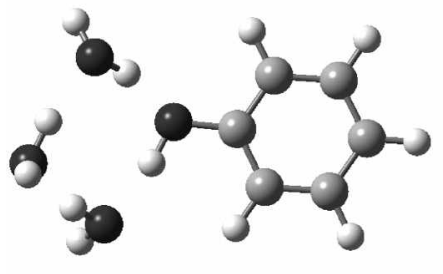

(P31)

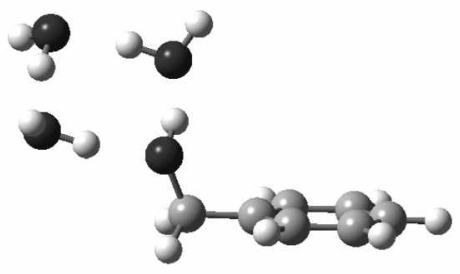

(B31)

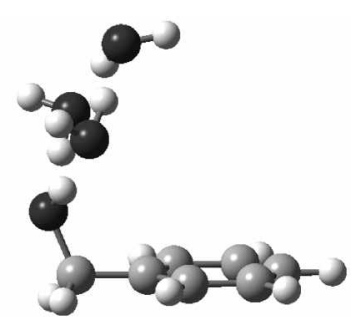

(B32)

Figure 4. Structures of lowest-energy phenol- and benzyl alcohol- $\left(\mathrm{H}_{2} \mathrm{O}\right)_{5}$ clusters

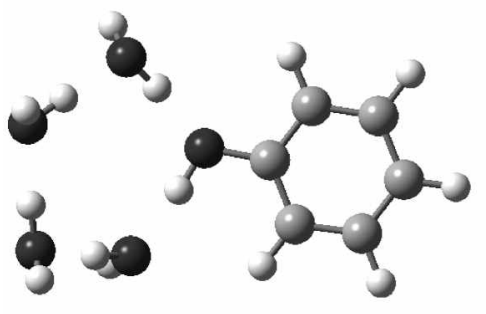

(P41)

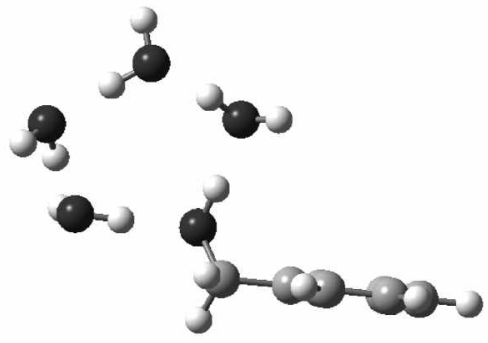

(B41)

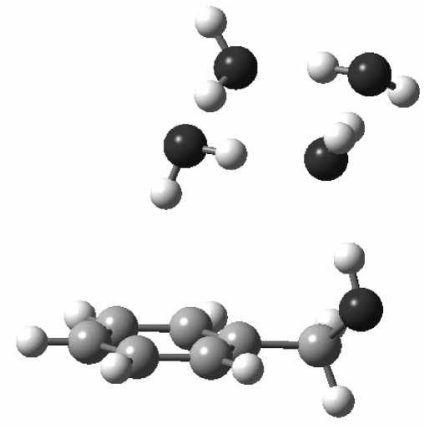

(B42)

Figure 5. Structures of lowest-energy phenol- and benzyl alcohol- $\left(\mathrm{H}_{2} \mathrm{O}\right)_{4}$ clusters.

energy is (B31) shown in Figure 4. In this isomer the three water molecules and the hydroxyl group form a ring. Since the ring lies away from the phenyl ring. $\pi$ bond cannot be formed between water and the phenyl ring in this isomer. The structures of the lowest energy phenol- $\left(\mathrm{H}_{2} \mathrm{O}\right)_{4}$ and the benzyl alcohol- $\left(\mathrm{H}_{2} \mathrm{O}\right)_{4}$ clusters are shown in Figure 5 . In the isomer $(\mathrm{P} 4 \mathrm{l})$ of the phenol- $\left(\mathrm{H}_{2} \mathrm{O}\right)_{4}$ cluster the five oxygen atoms of the hydroxyl group and the four water molecules form a 5-membered ring. The isomer (B42) discussed by
Mikani and coworkers ${ }^{28}$ contains $\pi$-bond between a water molecule and the phenyl ring.

As the carbon sidechain gets longer in the aromatic alcohol. the acidity of the hydroxyl group may decrease. rendering the energy difference between the isomer containing the protondonating $\mathrm{OH}$ and that with the proton-accepting $\mathrm{OH}$ group to become smaller. It is found that this energy difference is 2.61 and $1.55 \mathrm{kcal} / \mathrm{mol}$ for phenol- $\mathrm{H}_{2} \mathrm{O}$ and benzyl alcohol$\mathrm{H}_{2} \mathrm{O}$ complexes. respectively, demonstrating that this is
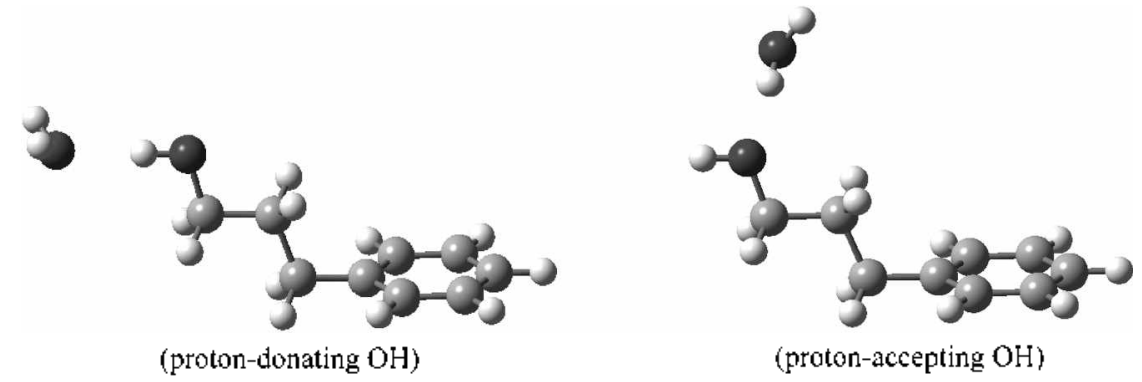

Figure 6. Structures of lowest-energy pheny lpropanol- $\left(\mathrm{H}_{2} \mathrm{O}\right)$ complexes. 
indeed the case. Figure 6 depicts the lowest-energy protondonating and -accepting conformers of the phenylpropanol$\mathrm{H}_{2} \mathrm{O}$ complex. ${ }^{29}$ with very small energy difference (only 0.07 $\mathrm{kcal} / \mathrm{mol}$ ) (MP2 /6-31+G**. ZPE-uncorrected). Since the carbon sidechain is quite floppy more numerous confonmers exist for this complex with much smaller energy differences than for phenol- $\mathrm{H}_{2} \mathrm{O}$ or benzy'l alcohol- $\mathrm{H}_{2} \mathrm{O}$ complexes.

Catechol-water clusters. Catechol-water clusters are quite intriguing because the catechol molecule possesses two close-lying hydroxyl groups. The two $\mathrm{OH}$ groups may act either as proton donor or acceptor or both. and the strength of the hydrogen bonding could be more versatile depending on the structure of the clusters. It is known that water molecules form cyclic structures with themselves. while only very few of them directly interact with the hydroxyl group in phenol- $\left(\mathrm{H}_{2} \mathrm{O}\right)_{n}$ system. For catechol-water clusters more water molecules may interact with the water molecules due to the presence of multiple functional groups. Also the intramolecular hydrogen bonding between the two alcoholic hydroxyl groups may' significantly influence the interactions between the hydroxyl-water interactions in the catechol-water clusters (for example. in terms of the binding energies). as compared with the phenol- $\left(\mathrm{H}_{2} \mathrm{O}\right)_{n}$ sy'stem. Detailed study on the configuration of the water molecules in the vicinity of the two hydroxyl groups may also give invaluable information for the themodynamic properties of the catechol molecule in aqueous solution. The catechol molecule exhibits many important biochemical functions such as nucleophilic catalysis of peptide bond formation. ${ }^{31}$ and the interaction with the water molecules may also reveal valuable information for the biochemical reactivity in aqueous solution.

Figure 7 presents the computed structure of the free catechol molecule. ${ }^{31}$ The two $\mathrm{OH}$ groups lie in the plane of the phenyl ring (that is. catechol is planar). The catechol molecule

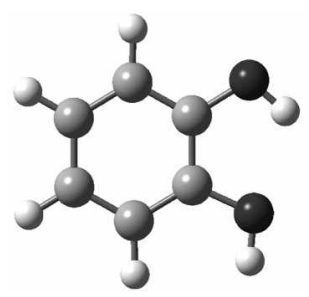

Figure 7. Free catechol.
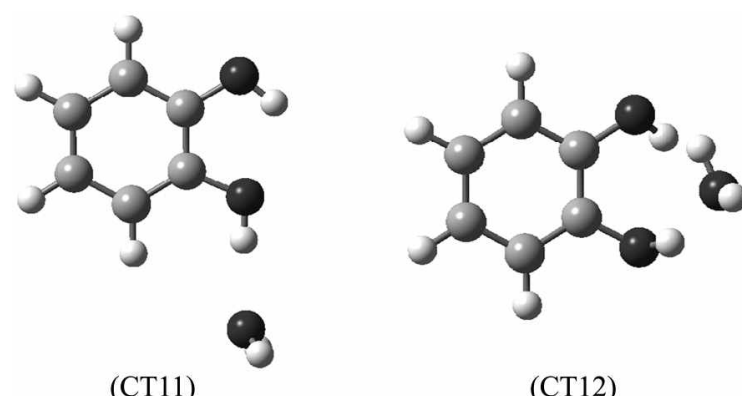

Figure 8. Structures of catechol- $\mathrm{H}_{2} \mathrm{O}$ complexes. possesses weak intramolecular hydrogen bonding between the hydrogen and the oxygen atoms. The hamonic frequencies of the two $\mathrm{OH}$ stretching modes calculated by BLYP/6$31+\mathrm{G}^{* *}$ method (without employing the scaling factors) compare very well with the experimental frequencies of 3611 and $3673 \mathrm{~cm}^{-1}$.32 For the catechol- $\mathrm{H}_{2} \mathrm{O}$ cluster (Figure 8), the most stable isomer is the structure (CT11) at BLYP/6$31+G^{* *}$ level of calculations. in which one of the two hydroxyl groups donates proton to the water molecule. The water molecule forms very weak bond with the orthohydrogen in the phenyl ring. The two $\mathrm{OH}$ bonds in the water molecule lie in perpendicular position with respect to the phenyl ring. The harmonic frequencies of the two $\mathrm{OH}$ stretching modes computed by the BLYP/6-31+G** method are 3621 and $3444 \mathrm{~cm}^{-1}$. In the next stable isomer (CT12) of catechol- $\mathrm{H}_{2} \mathrm{O}$. the water molecule interacts with two hydroxyl groups. forming a cycle. One of the $\mathrm{OH}$ groups acts as proton donor. The other $\mathrm{OH}$ group is proton acceptor whose hydrogen bonding is significantly weaker. The energy of this isomer is slightly higher than the most stable structure (CT11) by about $1.88 \mathrm{kcal} / \mathrm{mol}$ (ZPE corrected) at BLYP/6$31+\mathrm{G}^{* *}$ level of theory. The calculated hamonic frequencies of the two $\mathrm{OH}$ stretching modes are 3601 and $3357 \mathrm{~cm}^{-1}$ (BLYP/6-31+G**). Comparing the harmonic frequencies of these two isomers of the catechol- $\mathrm{H}_{2} \mathrm{O}$ cluster with the experimental frequencies of the two $\mathrm{OH}$ stretching modes ( 3597 and $3499 \mathrm{~cm}^{-1}$ ), the catechol- $\mathrm{H}_{2} \mathrm{O}$ cluster experimentally observed by Kleinermanns and coworkers can be safely assigned as the lowest energy structure (CT11), as discussed by them. ${ }^{32}$

For the catechol- $\left(\mathrm{H}_{2} \mathrm{O}\right)_{2}$ cluster. the most stable isomer obtained is the structure (CT21), in which the two hydroxyl groups and the two water molecules form a ring (Figure 9). In this isomer all of them act both as proton donors and acceptors. that is. each oxygen atom in the ring accepts a proton from a neighboring nember. and gives a proton to the next. Other isomers are also depicted in Figure 9. One of the intriguing questions concening the aromatic alcohol-water clusters is whether the $\pi$ bonding between water molecule and the phenyl ring is important or not. ${ }^{23}$ For the benzenewater clusters. this $\pi$ bonding is essentially the only possible interactions. because the benzene molecule does not possess another functional group. For phenol- $\left(\mathrm{H}_{2} \mathrm{O}\right)_{n}$ clusters. on the other hand the presence of the hydroxyl groups gives so strong hy'drogen bonding with the water molecules that the isomers exhibiting $\pi$ bonding are predicted to be much higher in energy than those containing a hydrogen bonding between the hydroxyl group and a water molecule and a ring consisting of water molecules. In the isomer (CT25). one of the water molecules interacts with the two hydroxyl groups. while the other lies above the phenyl ring. The energy of this isomer is. however. quite high, $5.05 \mathrm{kcal} / \mathrm{mol}$ above that of the most stable structure (CT21) at $\mathrm{HF} / 6-31+\mathrm{G}^{* *}$ approximation. The lengths of the hydrogen bonds in this $\pi$ bonding isomer are relatively longer than for other isomers presumably due to the geometrical constraints (that is. the accessibility of water to the phenyl ring) caused by the 


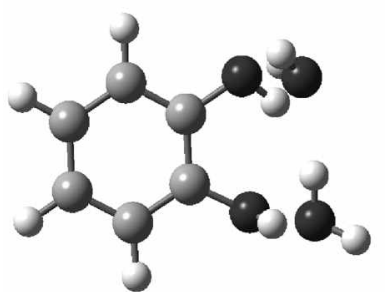

(CT21)

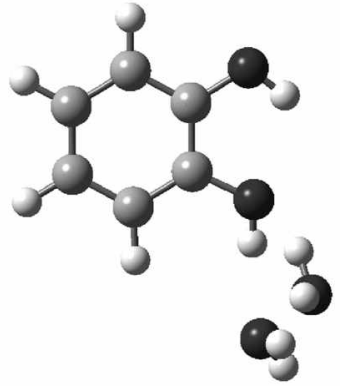

(CT22)

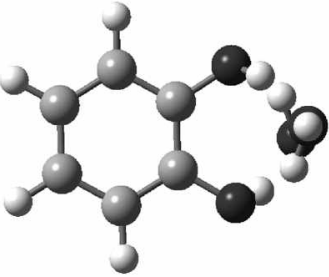

(CT23)

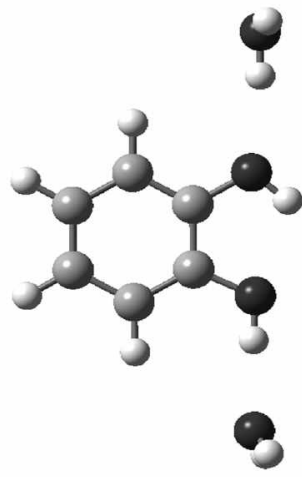

(CT24)

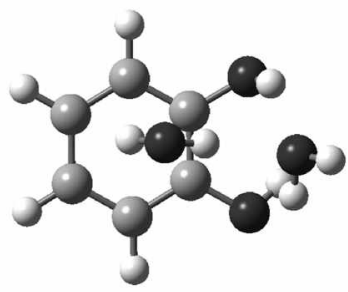

(CT25)

Figure 9. Structures of catechol- $\left(\mathrm{H}_{2} \mathrm{O}\right)_{2}$ clusters.

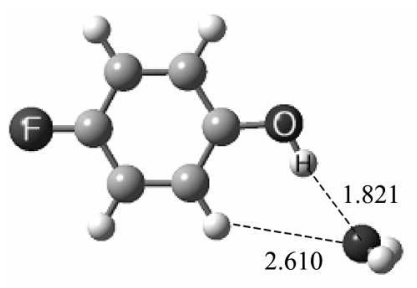

(FP11) proton-donating $\mathrm{OH}$

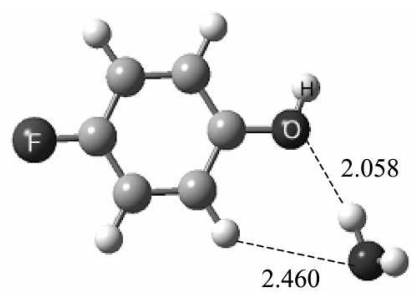

(FP12) proton-accepting $\mathrm{OH}$

Figure 10. Structures of p-flnorophenol- $\mathrm{H}_{2} \mathrm{O}$ compleses.

formation of the $\pi$ bond and the resulting increase in energy is not fully compensated by the bonding. Since the energy of the structure (CT25) is relatively higher than the low-energy structures. it may be inferred that this conformer including the $\pi$-bonding may not be important in low-temperature gas phase catechol- $\left(\mathrm{H}_{-} \mathrm{O}\right)_{2}$ cluster. although higher level theory must be employed to verify' this point clearly. lncrease in the number of clustering water molecules. however. may somewhat relax this geometrical constraints in the clusters containing more water molecules.

Other substituted phenol-water clusters. There have not been many studies for the other substituted phenol-water clusters yet. Lee and co-workers ${ }^{33}$ have recently investigated the effects of substitution at the phenyl ring on the strength of the hydroxyl-water hydrogen bonding systematically by calculating the binding energies of the complexes. For all the complexes studied. they predicted that those confomers with the proton-donating $\mathrm{OH}$ group will be of lower energy than the proton-accepting one. Table 1 presents the calculated results for p-fluoro-, p-chloro- p-aminophenol- and hydroquinone-

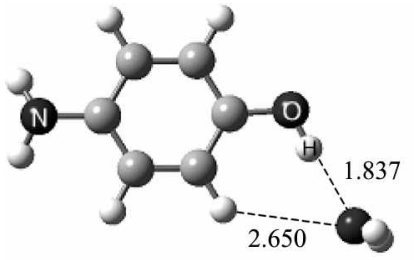

AP11 (proton-donating $\mathrm{OH}$ )

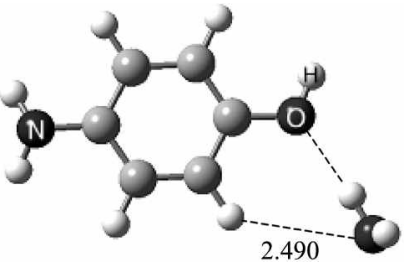

AP12 (proton-accepting $\mathrm{OH}$ )
Figure 11. Structures of $\mathrm{p}$-aminophenol- $\mathrm{H}_{2} \mathrm{O}$ complexes.

$\mathrm{H}_{2} \mathrm{O}$ complexes. and Figure 10 and Figure 11 depict the calculated structures of the p-fluoro- and p-aminophenol $\mathrm{H}_{2} \mathrm{O}$ complexes. respectively:

Based on a qualitative reasoning for the influence of substituting group at the para position on the strengths of the hydroxyl group as acid or hydrogen bonding basicity. it was predicted $^{33}$ that. when the hydrosyl group acts as protondonor (acid). the hydrogen bonding is strengthened by the electron-withdrawing group. On the other hand. when the $\mathrm{OH}$ group is proton-accepting the binding energy decreases because the hydrogen bonding basicity of the oxygen atom of the hydrosyl group is reduced due to the substituted fluorine. For the electron-donating groups. the reverse trend was predicted. They carried out calculations (by employing the MP2/6-311G** method) for $-\mathrm{F}$ and $-\mathrm{Cl}\left(-\mathrm{NH}_{2}\right.$ and $\left.-\mathrm{OH}\right)$ as electron-withdrawing (-donating) substituents. and found that their predictions are indeed correct. The changes in the binding energies due to the substituents were calculated to be about $0.5 \mathrm{kcal} / \mathrm{mol}$. Natural Population Analysis (NPA) for the p-substituted phenol- $\mathrm{H}_{2} \mathrm{O}$ complexes also corroborated 


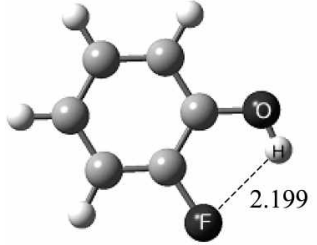

o-FP1

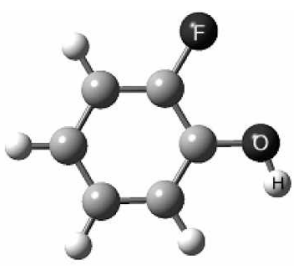

o-FP2
Figure 12. Structures of o-fluorophenol complexes.

their explanations. For the ortho-substituted complexes. the analy'sis is much more difficult. because the $\mathrm{OH}$ group and the substituent lie very close to each other. For example as depicted in Figure 12 for the o-fluorophenol. some confonmers may possess the intramolecular hydrogen bonding. while others may not. These differences in the geometrical arrangements of $\mathrm{OH}$. substituting group. and the binding water molecule may produce various effects to affect the strength of the hydrogen bonds in the complexes. In addition to the electrostatic effects the substituents may directly bond with the hydrosyl group or the water molecule or induce considerable change in the local structure near the hỵdrogen bonds.

The calculated infrared frequencies also exhibited very interesting pattern: It was found that the hamonic frequency of the stretching mode of the proton-donating $\mathrm{OH}$ group in the substituted phenol moiety in the complexes significantly decrease from that of bare substituted phenol (for example. while the $\mathrm{OH}$ stretching mode frequency of the p-fluorophenol is computed to be $3886 \mathrm{~cm}^{-1}$. that of the corresponding complex p-FP11 is calculated to be only $3706 \mathrm{~cm}^{-1}$ ), and that the harmonic frequency of the stretching mode of the proton-cic'epting $\mathrm{OH}$ group in the substituted phenol moiety in the complexes remained more or less the same as that of bare substituted phenol (for example. the hamonic frequency of the p-fluorophenol-water complex p-FP12, which possess proton-accepting phenolic $\mathrm{OH}$ group. is computed to be $3888 \mathrm{~cm}^{-1}$. while that of bare p-fluorophenol is computed to be $3886 \mathrm{~cm}^{-1}$ ). This latter observation may help elucidate the structures of the substituted phenol-water complexes by the infrared spectroscopic methods. determining whether the phenolic $\mathrm{OH}$ group is proton-donating or -accepting.

On the experimental side. the p-aminophenol- $\mathrm{H}_{2} \mathrm{O}$ complex was studied by Wategaonkar and co-workers. ${ }^{34}$ and by Gerhards and Unterberg. ${ }^{35}$ They found that the most stable conformer of the p-aminophenol- $\left(\mathrm{H}_{2} \mathrm{O}\right)$ complex is the one

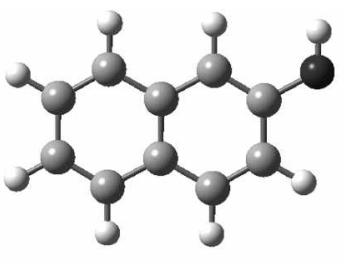

cis- $\beta$-naphthol
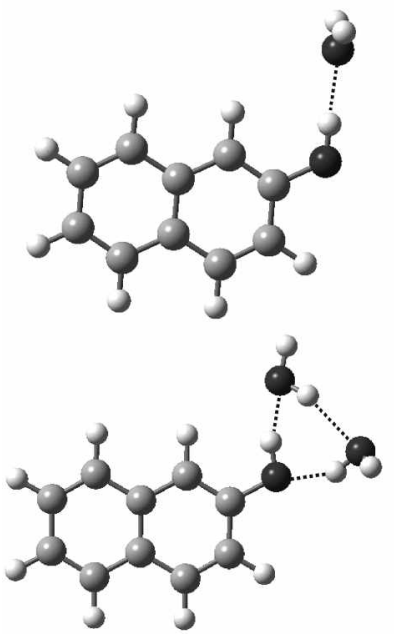

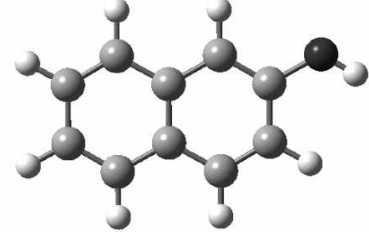

trans- $\beta$-naphthol
Figure 14. Structures of $\beta$-naphthol and $\beta$-naphthol- $\left(\mathrm{H}_{2} \mathrm{O}\right)_{\mathrm{n}}(\mathrm{n}=$ 1,2 ) clusters.

in which the $\mathrm{OH}$ group acts as proton donor (APll in Figure 11 ). in agreement with the predictions by Lee and coworkers ${ }^{33}$ The conformers with the water molecule binding to the amino group of the p-aminophenol moiety was calculated to be higher than AP11 or AP12, and they were not observed experimentally. Kleinemanus and co-workers ${ }^{36}$ studied the structures of the p-cresol- $\left(\mathrm{H}_{2} \mathrm{O}\right)_{1.3}$ clusters by two-photon resonant ionization spectroscopy in detail. The structures of the clusters they assigned are depicted in Figure 13. They found that the $(0,0)$ band of the $\pi-\pi$ transitions of the p-cresol- $\left(\mathrm{H}_{2} \mathrm{O}\right)_{1}$ cluster significantly (by $\left.357 \mathrm{~cm}^{-1}\right)$ red shifts from that of the bare cresol. while those of the pcresol- $\left(\mathrm{H}_{2} \mathrm{O}\right)_{2,3}$ clusters red shift to a lesser degree ( 107 and 76 $\mathrm{cm}^{-1}$, respectively). They explained this behavior of the electronic spectra by carrying out the $a b$ initio calculations for the HOMO-LUMO gap for the $\pi-\pi$ transitions. and by analyzing the effects of proton-accepting or -donating water molecule(s) on the HOMO and LUMO of the clusters. in good agreement with the experimental observations. They also found that the intermolecular stretching frequency (185
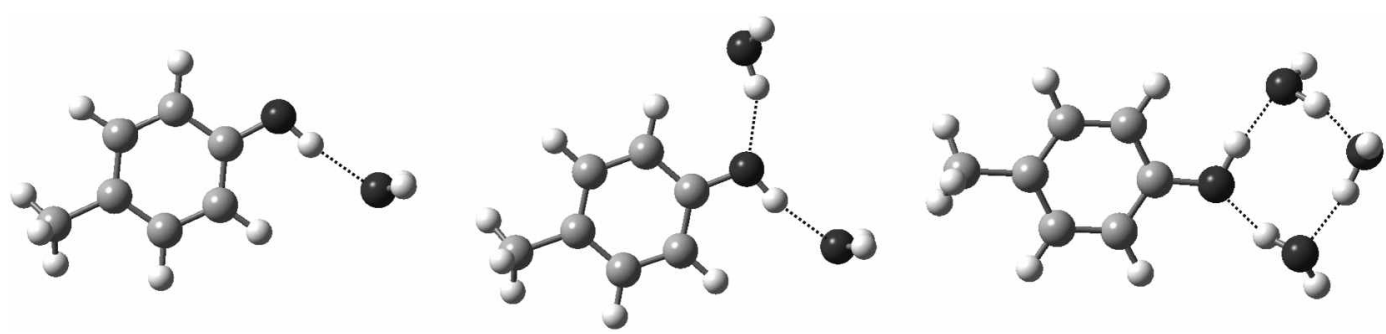

Figure 13. Structures of p-cresol- $\left(\mathrm{H}_{2} \mathrm{O}\right)_{h}(\mathrm{n}=1-3)$ clusters. 
$\left.\mathrm{cm}^{-1}\right)$ of p-cresol- $\left(\mathrm{H}_{2} \mathrm{O}\right)_{3}$ is significantly higher than that $\left(146 \mathrm{~cm}^{-1}\right)$ of $\mathrm{p}$-cresol- $\left(\mathrm{H}_{3} \mathrm{O}\right)_{3}$. and attributed this observation to the more rigid $\mathrm{O}-\mathrm{O}$ potential of the cyclic water trimer in p-cresol- $\left(\mathrm{H}_{2} \mathrm{O}\right)_{3}$ cluster

$\boldsymbol{\beta}$-Naphthol-water clusters. The $\beta$-Naphthol- $\left(\mathrm{H}_{2} \mathrm{O}\right)_{\mathrm{n}}(\mathrm{nl}=$ 1-3,5) clusters were investigated by Mikami and coworkers ${ }^{37}$ both experimentally and computationally. By employing the IR-UV double resonance technique. they observed the hydrogen-bonded $\mathrm{OH}$ stretching frequencies. and assigned the structures of the clusters by comparing with the ab initio calculations. As in the case of p-cresol-water clusters discussed above. the $(0,0)$ band of $\beta$-Naphthol$\left(\mathrm{H}_{2} \mathrm{O}\right)_{1}$ shifts to red from that of bare $\beta$-Naphthol. while those of the clusters with $n \geq 2$ blue shift with respect to that of the $n=1$ cluster. The bare $\beta$-Naphthol molecule may exhibit two rotamers. cis- and trans- as depicted in Figure 14. Of the two rotamers. the cis-form is of lower energy, and the measured population ratio of the cise and trans-forms was 3:1. The assigned structures for the $\beta$-Naphthol- $\mathrm{H}_{2} \mathrm{O}$ cluster are also shown in Figure 14. In both structures. the $\mathrm{OH}$ group in the naphthol moiety is proton-donating. The weakening of the $\mathrm{OH}$ bond is observed as red shifts (by 142 and $138 \mathrm{~cm}^{-1}$. for cis- and trans-forms. respectively) from that of the bare $\beta$-Naphthol. The $\beta$-Naphthol- $\left(\mathrm{H}_{3} \mathrm{O}\right)_{2,3}$ clusters were assigned to contain three-membered, and fourmembered water ring, respectively, while the structure of the $\beta$-Naphthol- $\left(\mathrm{H}_{-} \mathrm{O}\right)_{5}$ cluster was predicted to be of ice (l) type.

Tropolone-water clusters. The tropolone-water clusters contain both intramolecular and intermolecular hydrogen bonds. and thus it proved quite intriguing to study how the internnolecular hydrogen bond between water and tropolone affects the intramolecukar hydrogen bonding between the $\mathrm{OH}$ and the carbonyl groups in tropolone. Mikami and coworkers, ${ }^{38}$ and Zwier and co-workers ${ }^{39}$ carried out extensive investigations for the tropolone $-\left(\mathrm{H}_{2} \mathrm{O}\right)_{n}(n=1-3)$ clusters to determine their structures by the IR-UV double resonance

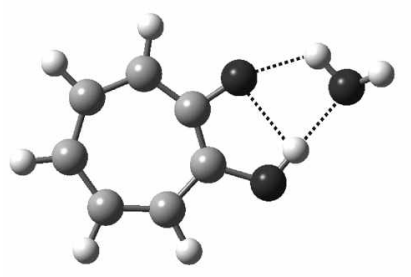

TP11

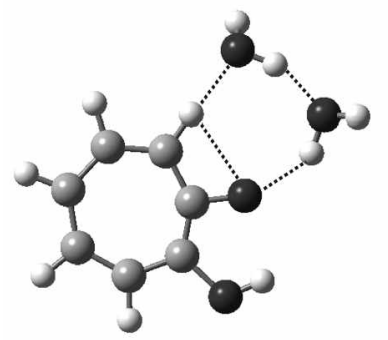

TP21

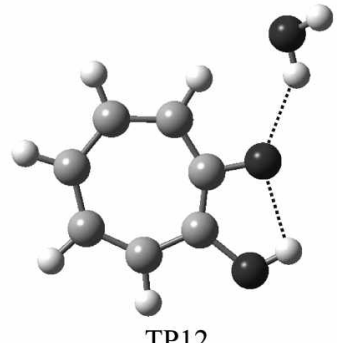

TP12

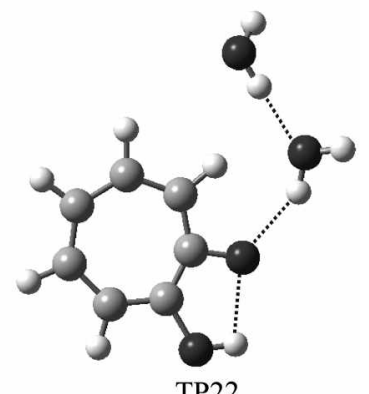

TP22
Figure 15. Structures of tropolone- $\left(\mathrm{H}_{2} \mathrm{O}\right)_{h}(11=1,2)$ clusters. spectroscopy. The former group found that the $(0,0)$ frequencies for the tropolone- $\left(\mathrm{H}_{2} \mathrm{O}\right)_{n}(n=1-3)$ clusters blue slift more and more $\left(289,451\right.$ and $623 \mathrm{~cm}^{-1}$. respectively, for $\left.\mathrm{n}=\mathrm{l}-3\right)$, indicating that tropolone acts as proton acceptor in these clusters. By observing that the IR spectra for the tropolone$\left(\mathrm{H}_{2} \mathrm{O}\right)_{1}$ cluster exhibited two distinct band for the two $\mathrm{OH}$ stretching modes of the water moiety, the two groups proposed TPII and TPI2 (Figure 15) as the probable structures for the tropolone- $\left(\mathrm{H}_{2} \mathrm{O}\right)_{1}$ cluster. Preference of the two groups differed (for example. Mikami and co-ivorkers ${ }^{38}$ preferred the structure TPII on the basis of several spectroscopic arguments and by comparing the IR spectra for the tropolone$\left(\mathrm{CH}_{3} \mathrm{OH}\right)_{1}$ cluster, while Zwier and co-workers ${ }^{39}$ expressed slight preference for TP12), however, and further detailed analy sis would be needed for unambiguous elucidation of the structure. For the tropolone- $\left(\mathrm{H}_{2} \mathrm{O}\right)_{2}$ cluster, Mikami and co-ivorkers proposed TP21 and TP22 as the two most probable structures. but definite assignment was not made. Based on the fact that the aqueous solution of tropolone is slightly acidic $(p \mathrm{Ka}=6.7)$. Mikami et al. suggested that the intramolecular hydrogen bond in tropolone would break to free the $\mathrm{OH}$ group as a proton donor to the water molecule. $\mathrm{By}$ inferring that the stretching frequency of the tropolone $\mathrm{OH}$ in the tropolone- $\left(\mathrm{H}_{2} \mathrm{O}\right)_{n}$ cluster dramatically increases to about $3300-3500 \mathrm{~cm}^{-1}$ from that $\left(-3100 \mathrm{~cm}^{-1}\right)$ of the tropolone- $\left(\mathrm{H}_{2} \mathrm{O}\right)_{n}(\mathrm{n}=0-3)$ clusters, Mikami et al. indicated that the intramolecular hydrogen bond in tropolone would indeed break in the former cluster. By comparing the spectra for the tropolone- $\left(\mathrm{CH}_{3} \mathrm{OH}\right)_{3}$ cluster, they also proposed a ring structure for tropolone- $\left(\mathrm{H}_{2} \mathrm{O}\right)_{3}$.

\section{Concluding Remarks}

Since the isomers of aromatic alcohol- $\left(\mathrm{H}_{2} \mathrm{O}\right)_{7}$ clusters are of similar energy, at most within a few $\mathrm{kcal} / \mathrm{mol}$, the analysis of the experimental observations is usually nontrivial. The interplay between calculations and experimental observations is thus very important to unambiguously elucidate the structures of the clusters. Systematic studies on the hydrogen bonding in small clusters would also shed considerable light to the stnuctures and reactions of organic and biomolecules in the solution phase. Therefore. more extensive studies for this interesting sy'stem would be highly desirable.

Acknowlegments. This work was supported by Korea Research Foundation Grant (KRF-2002-070-C00046).

\section{References}

1. Pimental. G. C.: McClellan. A. L. The Hydrogen Bond: Freeman and Company: San Francisco, 1960.

2. Zwier, T. S. Amm Rev Plys. Chem 1996. $+7,205$

3. Trotonda, F. R:; Pascual-Ahuir. J. L:; Silla. E.; Tunon. I. Chen. Phs Lett. 1996. 260.21.

4. Bandyopadhyay. P.: Gordon. M. S.: Mentucei. B.: Tomasi. I. /. Chem. Phus 2002. 116.5023.

5. Park. S.W: Ahn. D.-S, Lee, S. Chem Plys Lett. 2003. $371,74$.

6. Lee. K. T.: Sung. J.: Lee, K. J.: Kim. S. K.: Park. Y. D. J. Chem Phos 2012, 116,8251 . 
7. Scheiner, S.: Kar. T: Pattanayak, J. J. Am. Chem Soc. 2002, I2t. 13257.

8. Schutz. M.: Burgi. T.: Leutwyler. S.: Fischer. T. J. Ghem. Phns. 1993. 98.3763

9. Barth. H.-D.: Buchlold K.: Djafari. S.: Reimann. B.: Lommatzsch. U.: Brutschy, B. Chem. Phws, 1998, 239.49.

10. Auspurger. J. D.: Dykstra, C. E. Zwier T. S.J. Phs Chem 1993. 97.980 .

11. Fredericks. S. Y: Jordan. K. D.: Zwier. T. S. J. Phns. Chem. 1996. 100.7810.

12. Garrett. A. W: Zwier T. S. J. Chen. Phns, 1992.96.3402.

13. Kim, K. S. Lee. I. Y: Choi. H. S.: Kim, J: Jang. J. H. Chent. Phis. Lett 1997. 265,497 .

14. Garrett. A. W: Severance D. L.: Zwier T. S. J. Chem. Phys 1992. 96. 7245

15. Janzen. Ch.: Spangenberg. D.: Roth. W: Kleinermantns. K. J. Chem. Phys. 1999.110.9898.

16. Jansen, Ch: Gerhards, M. J. Chem. Phns, 2001. 115,5445

17. Watanabe, H.: Iwata, I. $J$. Chem Plws. 1996. $105,420$.

18. Watanabe. T: Ebata. T: Tanabe. S; Mikani. N. J. Chem. Phvs. 1996. 105,408

19. Gerhards. M.: Kleinermanns. K. J. Chem. Phns. 1995. 103.7392

20. Watanabe. T.: Ebata. T: Fujii. M:: Mikami. N. Chem. Phvs. Lett. $1993,115,347$.

21. Feller D: Fevereisen. M. W. J. Contp. Chent 1993, 14, 1027

22. Oikawa. A.: Abe. H.: Mikani. N.: Ito, M. J. Phns. Chem. 1993. 87.1027.

23. Tarakeshwar. P.: Kim. K. S.: Kraka. E.: Cremer. D. J. Chem. Phns. 2001. 115.6001

24. Cheong W. J.: Kim C. Y. Bull Korean Chem. Soc. 2000. 21, 351: Lee, C. S.: Cheong. W. J. J. Liq. Chront \& Ret. Technol 1999. 22.
253: Lee. C. S.; Cheong, W. J. J. Chromatogr A 1999, 8+8. 9; Lee C. S.: Cheong. W. J. J. Chrontatogr A $2001,848,9$

25. Wickleder. C.: Henseler. D.: Leutwyler. S. J. Chem. Phus. 2002. 116. 1850 .

26. Wade. E. A.: Kline. J. I.: Lorenz. K. T.: Hayden. C.: Chandler. D W. J. Chem. Phvs. $2002,116,4755$.

27. Braun. J. E; Mehner, Th.: Neusser, H. J. Infl, J. Mass Spectront 2000. 203, 1

28. Guchhait. N.: Ebata. T.: Mikami. N. I. Chem. Phus. 1999. 11 . 8438.

29. Teonl. I.-S.: Ahr1. D.-S.: Park. S.-W.: Lee. S. (unpublished).

30. Ivanova, G.; Bratovanova, E.; Pethov, D. J. Peptide Science 2002. 8. 8 .

31. Jang. S.-H; Park, S.-W: Kang, J.-H; Lee, S. Bull. Korean Chen Soc. 2002. 23. 1297.

32. Gerhards. M.: Unterberg. C.: Kleinermant1s. K. Plys. Chem. Chem. Phus. 2000. 2.5544.

33. Ahn, D.-S.: Park. S.-W.: Lee, S.: Kim, B. J. Phys. Chem. 2003. A107. 131

34. Meenakshi. P. S: Biswas. N.; Wategaonkar. S. J. Chent. Phys 2002. 117.11146

35. Gerhards. M.: Unterberg. C. Appl. Phus. A 2001. 72. 273.

36. Gerhards. M.: Kimpfèl. B.: Pohl. M.: Schmitt. M.: Kleinermanns. K. J. Mol. Struct 1992. 270.301

37. Matsumoto. Y.: Ebata. T., Mikami. N. J. Chent. Plns. 1998, 109. 6303 .

38. Mitsuzuka. A.: Fujii. A.: Ebata. T:: Mikami. N. J. Chem. Phys. 1996. 105. 2618 .

39. Frost. R. K.: Hagemeister. F.: Arrington. C. A.: Schleppenbach. D.: Z wier. T. S. J. Chem Phvs. 1996, 105. 2595, 1996, 105, 2605. 